\title{
Bookmakers and a Duty of Care: Customers' Views in England
}

\begin{abstract}
This paper focuses on customers' views on the extent that bookmakers and individuals are responsible for a duty of care. 72 participants from seven bookmakers in one city in England were interviewed that illustrates customer's expect bookmakers to take 'reasonable steps' to avoid exploiting all customers. However, the customers' views recorded in this paper illustrate a range of views on what a duty of care should actually comprise with differences of opinion on the level of bookmakers and individuals' level of responsibility, dealing with intoxicated customers, illegal gambling, prevention of excessive and problem gambling and self-exclusion.
\end{abstract}

\section{Key Word: Bookmakers, Gambling, Duty of Care, Self-Exclusion, Profit}

\section{Introduction}

There is international research on whether a gambling venue should owe a duty of care to its customers. These mostly focus on a some aspect of self-exclusion (Napolitano 2003; Bauer 2006; Sasso and Kalajdzic 2006; Cameron 2007; Kalajdzic 2008; Mohammed 2008; Crowne 2008), what a policy of self-exclusion should offer (Collins and Kelly 2002; Rhea 2005; Ladouceur, Sylvain and Gosselin 2007; Gainsbury 2014), the details of a casino self-exclusion program (Ladouceur et al. 2000), how effective a self-exclusion program is or should be (Nelson et al. 2010; Hayer and Meyer 2011), law suits (Faregh and Leth-Steensen 2009) and self-imposed limits and gambling on the internet (Nelson et al. 2008).

There is, however, little on customers' views on what a duty of care should comprise prior, throughout and beyond self-exclusion. This is important for a number of reasons, as a duty of care should be about more than self-exclusion: (1) current customers that manifest no visible gambling problem can become those requesting self-exclusion in the future and hence knowledge, or lack of it, on what a duty of care should comprise is worthy of attention (2) knowledge or lack of knowledge on what a duty of care comprise illustrates limited awareness of avenues to minimise harm (Hayer and Meyer 2011) by customers and/or poor advertising of a much needed service by bookmakers (3) all customers, regardless of whether they have requested self-exclusion need protecting from excessive gambling (Orford 2001) and hence a duty of care for all customers' gambling in bookmakers and attitudes regarding service is critical.

The current legal position, however, is one that favours gambling establishments with the emphasis on individuals, and particularly those with a gambling problem to abstain from all gambling if challenging a gambling establishment's breach of a duty of care (see Calvert $v$ William Hill Credit Ltd, 2008; Gambling Commission 2014). The expectations of all customers regardless 
of the severity of the problem, however, of what a duty of care should entail is sometimes absent in the material.

We therefore start to examine this problem by providing the current legal definition of a duty of care. This is followed by an explanation of our methodological approach and the issues we encountered working 'in the field'. Then, we present the analysis of the results which illustrate that customers empathise with people with a gambling problem seeking self-exclusion but also highlight a range of views on the level of bookmakers and individual's personal level of responsibility, dealing with intoxicated customers, illegal gambling, prevention of excessive and problem gambling and self-exclusion.

\section{A Duty of Care}

A duty of care is legally defined as a relationship between a company and a claimant rather than with a class of claimants with a gambling problem. The notion of a duty of care was defined in the Calvert $v$ William Hill Credit Ltd case as where a "Bookmaker who has at the customer's request, undertaken to prohibit the customer from gambling for a specific period, owes the customer a duty to take reasonable care to enforce that prohibition to protect them from the risk of gambling losses during the specified period" (Calvert $v$ William Hill Credit Ltd, 2008: EWHC 454).

A duty to prevent excessive gambling should exist before reaching the stage of self-exclusion. Such a duty might include placing leaflets on the dangers of gambling in set locations in bookmakers, notices on Fixed Odds Betting Terminals (FOBTs) and posters of GamCare helpline on ATM machines. A selfexclusion arrangement, however, constitutes an 'active intervention into the life' of the individual (Bauer 2006:90) and therefore when a request is made to the bookmaker(s) they should owe a duty of care to fulfil this process as they have recognised that the individual, unless prevented, will succumb to problem gambling. Once reaching the stage of self-exclusion, however, an individual will already have a gambling problem and no doubt suffered both financial and personal loss

In the Calvert case William Hill failed to implement a duty of care policy correctly but it was seen by the court as unfair that a bookmaker that entered into such an arrangement 'without any disclaimer of liability, should incur a duty of care'. Failure to implement the policy was viewed as careless with William Hill responsible for it, but it was considered imperative that self-exclusion not be seen as a means of transferring responsibility for excessive gambling (Collins and Kelly 2002: 517) onto bookmakers.

A bookmaker's liability then depends on specific knowledge of their customers. However, if bookmakers are unaware customer(s) are suffering from a gambling problem, harm is not foreseeable and no liability is incurred. Furthermore, it is considered that problem gambling 'may mean no more than... "experiencing mild and occasional difficulties of control" by the court and is the reason put forward why no duty should be owed to those individuals whose condition is considered severe enough to constitute pathological gambling, 
when "even its most serious sufferers have periods of relative clarity" (see Calvert V William 454 (Ch) Para 170). Individuals with a gambling problem then must be responsible for their own actions regardless of the seriousness of the gambling problem.

Whilst bookmakers currently owe a regulatory duty to the Gambling Commission to undertake business in a socially responsible manner, and act as an effective deterrent to prevent the exploitation of customers - because if breached, the commission could use its powers to remove their licence or to issue a financial penalty - simply owing a duty, which is enforceable by the Gambling Commission, is a limited solution. Whilst it provides a mechanism to regulate bookmakers' behaviour, a duty of care still appears open to interpretation to such an extent that even those with an obvious and identifiable gambling problem are expected to be personally logical and responsible. Consequently, due to the current legal view of problem gambling (Brooks and Blaszczynski 2011) an individual with a gambling problem is cut adrift.

Furthermore, the Gambling Prevalence Survey of 2010 in Great Britain (Wardle et al. 2011) noted that 81 percent of the 7,756 peopled surveyed preferred gambling 'in-person' (i.e., placing a bet in a betting shop, a casino or purchasing lottery tickets or scratch cards in a shop) and whilst bookmakers can visibly see excessive behaviour, the onus is still on the individual to 'control' his/her addiction.

\section{Methods}

A total of 72 customers in a nine month period in seven bookmakers in one city in England were interviewed. Of the seven bookmakers five are nationally established bookmakers and two independent. The numbers of people interviewed in individual bookmakers differs depending on the location of the bookmakers. For example, one shop was located in a central city positon, close to a selection of public houses and a small supermarket and provided 22 of those interviewed. It was decided that independent bookmakers also needed to be included in the research to see if the customers that frequented these bookmakers had a different view on a what duty of care should comprise from a bookmaker(s) such as a more personalised service. There were, however, no noticeable differences between national and independent bookmakers.

The interview schedule was designed with two sections; background data which consisted of age, approximate estimate of years gambling, ethnicity, employment status, preferred type of gambling of the customers and a following section that sought customers' views on what a duty of care should consist of and Likert scale statements ranked 1-5. These statements referred to the exploitation of customers, illegal acts by bookmakers, preventing underage gambling, self-exclusion, a duty of care towards those customers with a known gambling problem and dealing with intoxicated customers.

The Likert scale statements were established by an internal university pilot on four willing colleagues. Volunteers were requested via the email system of which four were selected for having some experience of gambling. Ten statements 
were designed to elicit responses on customers' views and a knowledge, or lack of it, regarding a duty of care that were preselected based on key recurring issues established from the literature review and Calvert case. It was intended that each statement should cover a key issue regarding a duty of care. Three statements were dismissed, however, due to feedback that illustrated that they were too similar and that a reduction in statements was thought necessary if interviews were to be completed due to limitations of research locations.

Access to customers was established with the guaranteed anonymity of the bookmakers in which the research was completed and that of the customers. Due to commercial sensitivity and customers' views of a duty of care this is perhaps understandable. Whilst not ideal, this research was not possible without local bookmaker's permission.

Once access was granted all customers were approached in the bookmakers by one of the research team. All customers in the bookmakers were informed of the aim of the research 'to access customers' views on what a duty of care should comprise and informed that no personal details were required but some background data was helpful to the research. We followed a similar research pattern in all the bookmakers. With the help of the bookmakers 'regular' customers were approached by one of the research team. This research produced some interesting results and provided some explorative, qualitative and descriptive data. While it is beneficial to have a personal contact as a 'gatekeeper' it can, however, influence the direction and sample of the research in a number of ways; they can limit access and conditions of entry in a social community, limit access to people and data and restrict the scope of analysis (Bulmer 2003; Brooks, 2012; Farooq and Brooks 2013; Belaisha and Brooks 2014). In this research, however, the bookmakers were needed as 'gatekeepers' to access customers' views.

There are, however, some limitations to this research. Due to the research locations some customers put themselves forward for an interview and as such wanted to voice an opinion. The numbers of customers approached by the research team were $45(62.5 \%)$ with $27(37.5 \%)$ of customers approaching the research team. It was noted at the time which of our customers approached the research team but after analysis there was no difference as to the level of criticism regarding a duty of care between these two groups. In addition some of the interviews were stopped whilst a race was in progress or a customer wanted to 'read the form' (of the horses), and restarted once this was complete.

Furthermore, there were no female customers in the research. This, however, reflects gendered gambling choices: the Gambling Prevalence Survey (2012) illustrated that women preferred gambling online rather than in male dominated environments such as bookmakers. This preference has been documented elsewhere (Widyanto and Griffiths, 2006; Bernardi and Pallanti, 2009), which illustrated the attractions of anonymity, accessibility and privacy (Corney and Davis, 2010) to women. These 'social' preferences though have the potential for increased and hidden gambling addiction in the female population. 


\section{Results}

Prior to the Likert scale statements background data on the customers were collected. This consisted of age, approximate estimate of years gambling, ethnicity, employment status and preferred type of gambling and frequency of gambling. The bookmakers were visited a total of fourteen times in a nine month period. Depending on the time of day, a particular race meeting and the changing seasons all affected the numbers of customers interviewed i.e. midafternoon, July meeting at Goodwood or early afternoon, Cheltenham Festival.

In addition all quotes are signified by a capital $P$ in the research and number of customer interviewed (i.e. P50) to illustrate the origin of the quote below. The age range of the customers were 18-21 $(n=5,6.9 \%)$ (referred to as Category 1 etc.), 22-30 ( $n=11,15.2 \%)$ (Category 2), 31-40 ( $n=5,6.9 \%)$ (Category 3), 41-50 $(n=7,9.7 \%)$ (Category 4), 51-60 ( $n=23,31.9 \%)$ (Category 5) and 61-70 $(n=21$, 29.1\%) in (Category 6).

The decision was made by the research team that only brief background data was possible to collect due to a number of factors; we wanted to make sure the customers completed the interview schedule and move on to the customers' views' section as quickly as possible, as we were researching in an environment we could not completely control, and that we were encroaching on customers' 'leisure time'. The research environment has, however, hindered the results to some extent. Researching in such a public space meant a lack of customers' personal privacy and the ability to record confidential views. Many customers in the research, however, were familiar with one another and regularly attended the same bookmakers and interacted with customers and staff on a regular basis and illustrated no signs of inhibition. Many approached the researcher $37.5 \%$ of sample) and wanted to offer a point of view, with criticism of bookmakers willingly given in front of fellow customers and bookmakers' employees. We also considered attempting to measure the number of customers that were experiencing a gambling problem as well. This was dismissed, however, due to limitations of the research locations, our inability to offer confidentiality, limited time to interview customers and the key aim of the research which was primarily to establish customers' views on a bookmakers' duty of care. The number of customers gambling daily, however, $(n=30)(41.6 \%)$ in our sample is a potential indication that some of the customers had a gambling problem.

Substantial numbers of the customers were in the last two age ranges (51-60 and $61-70)(61 \%)$ of the total number of people interviewed. Many of these were retired and as a few claimed '(P23) my kids have left home, it's just me and the missus, now, and (P41) 'I stopped gambling for some years as had a family', but now I can afford it again and (P60) 'I've nothing much to do now, come down here and have a bet and a chat with some of the others (meaning customers).

The numbers of years people were gambling ranged from 2-45 years. The data mostly followed a pattern with older customers gambling for many years and the youngest in the sample the least amount of years. The numbers of years some of the customers had been gambling were also often rounded (i.e., 20 years) by themselves rather than exact. Some of the customers also made it clear that there were also periods in their life when they stopped gambling. 
These often consisted of (P48) 'got divorced, didn't I! Couldn't bleeding afford it, could I.' (P64) 'Had a family, and 'terrible losing streak, had to walk away'. The length of period that these customers were gambling then are more of a rough indication with the newest able to recall exactly how many years they had been gambling.

The ethnicity of the customers were 63 (87.5\%) white British, with 8 (11.1\%) black British, 1 (1.3\%) Asian British; there were no women included in this survey. All bookmakers, however, employed women in some capacity.

Of the 72 customers 11 (15.2\%) were unemployed, 11 (15.2\%) in casual/seasonal employment and 23 (31.9\%) self-employed, 4 (5.5\%) from retail, $2(2.7 \%)$ professionals, and 21 (29.1\%) retired. In the section on background data we only requested customers to respond if they were employed, rather than specific type of employment. The breakdown of the above data is thus based on customers' willingly informing the research team of type employment status.

Of the 72 interviewed, 61 (84.7\%) preferred horseracing, $5(6.9 \%)$ had a preference for greyhound racing and 6 (8.3\%) claimed no preference. A few of those interviewed admitted playing Fixed Odd Betting Terminals (FOBT) in between races but none claimed they were a preference. There was, however, a noticeable age difference and employment status of the customers playing these machines. Those that fell into the 18-21, 22-30 and 31-40 age range played the FOBT (P11) 'every now and then', (P17), or passing time in-between races'. Those in the older age ranges were highly critical of the FOBTs and suggested that they should be removed (P51) 'a bloody nuisance, don't know why they play them'. Of the 11 (15.2\% of those interviewed) that were unemployed $8(72.7 \%)$ played FOBTs, the highest rate of play by employment type. Questioned why they played FOBTs (P1) 'I can play for small stakes which I can afford, and (P20) 'I enjoy playing alone' and (P52) 'in here (meaning bookmakers) I play with some of the others, you know, a group of us round the machine...for company like. The numbers playing FOBTs and unemployed in this research is of concern; however, it is not the aim of this paper to consider these data. The capacity for FOBT to be addictive has been amply illustrated elsewhere (Wardle et al. 2011).

The frequency of gambling was measured on a daily, weekend, weekly, every two weeks, and a one-month period. If a person did not bet on at least a monthly basis they were discounted from the research. Of the 72 interviewed 30 (41.6\%) bet on a daily basis, 15 (20.8\%) weekly, 9 (12.5\%) on the weekend, 9 every two weeks $(12.5 \%)$ and $9(12.5 \%)$ monthly. The self-employed and those that were retired mostly placed bets on a daily basis. Seen as a comfortable environment in which to (P70) 'have some fun and relax, talk to the youngsters' and (P58) 'get out the house', 'somewhere to go', social interaction was highly valued and used as an explanation for gambling daily. However, these types of responses echo the work of McNeilly and Burke (2000) that illustrated retired and older adults that frequented gambling venues often showed signs of disordered gambling.

The explanations offered by customers that placed a bet on a regular, mostly daily basis were (P48) 'it's a bit of fun for me', nothing large, you know, a few small bets', keeps the interest', (P30) 'I always have an accumulator, small 
stakes', and (P70) 'I prefer a Patent, hoping I might get one up' (a Patent is a type of bet that consists of seven bets; three individual wins, three doubles and one accumulator).

Analysing rates of participation and views on a duty of care illustrated a tendency for those that frequented bookmakers routinely to be far more critical than those that accessed bookmakers at weekends, every two weeks or monthly. 'Regular' customers made it clear that they thought they were 'entitled' to a duty of care but also a service: (P71) 'With the money I spend here I pay for their wages, the least they could do is provide some kind of service. Pushed on what was meant by 'service', the customer simply meant customer service (i.e., taking of bets right near start of race).

In the next section of the interview schedule customers were offer the chance to say what a duty of care should comprise. The customers were asked what a duty of care should consist of, without any guidance from the research team. We did not consider it appropriate to be prescriptive as we sought customers' own views on what a duty of care meant to them. A range of views were (P3) ' $a$ system to protect me from myself', (P24) 'Don't encourage gambling', or target the vulnerable (P32) 'Don't take advantage of us', with a few (P46, 62, 70, 71) stating 'we're responsible really but there needs to be a system of financial redress', if bookmakers know we are gambling beyond our means'. These customers tended to be old and/or retired and frequented the bookmakers daily.

Once these were completed the customers responded to the Likert scale statements which ranged from 1-5. The majority agreed or strongly agreed with the statement that 'Bookmakers owe a duty of care not to exploit all customers'. Of the 72 customers 56 (77.7\%) agreed while 16 (22.2\%) strongly agreed with this statement. All customers was emphasized here to see if they considered all those that enter a bookmakers are entitled to the same level of care as someone with a gambling problem. These views were supported by strongly agreeing (68) (94.4\%) and 4 (5.5\%) agreeing with the statement that a 'Bookmakers owe a duty of care not to exploit customer(s) with a gambling problem.

The statement 'Bookmakers that breach a duty of care are acting illegally' received a slightly mixed response. Of the 72 participants 39 (54.1\%) agreed that this was the case, with 14 (19.4\%) strongly agreeing and 5 (6.9\%) neither agreeing nor disagreeing and 14 (19.4\%) disagreeing that this was the case. Of those 14 that disagreed with this statement 10 of them referred to the Calvert case. On further analysis these 10 admitted to gambling daily and were either in the age bracket $40-50(n=2), 50-60(n=3)$ or retired $(n=5)$.

There was a mixed response to the statement 'Bookmakers should refuse bets from people with suspected gambling addiction'. The majority neither agreed nor disagreed (35) (48.6\%), 'those disagreeing (9) (12.5\%), those agreeing (7) (9.7\%) and those that strongly agreed (21) $(29.1 \%)$ to this statement. A few quotes from those that disagreed explained that (P33) 'you can't go around guessing if someone has a problem', I mean I come here all the time, but don't bet on every race, its social you know. This was further supported by other customers saying (P22) 'I'd be right pissed off if they refused my bets and told me they thought I had an addiction! 
However, the following statement that 'Bookmakers should refuse bets from people with a known gambling addiction' received a clear response but with questions raised by some of the customers. While 70 (97.2\%) strongly agreed with this statement and $2(2.7 \%)$ agreed some of the older customers raised concern that (P31) 'How do you know? Do they have actual medical diagnosis? This was echoed by (P58) 'Is it official? I mean what is acceptable? And what will the bookmakers accept?

Moving onto matters of self-exclusion the following statement 'Bookmakers should communicate an individuals' request for self-exclusion to all other bookmakers' the response was 63 (87.5\%) strongly agreeing and 9 (12.5\%) agreeing. However, some had doubts as to how this was to be achieved and bookmaker's willingness to process this information: (P2) 'it should happen, but can they be bothered to do this? I mean there's no guarantee they'll do it for their own business (in bookmakers and online) let alone another company'. Some of the customers were far more critical (P10) 'I agree with it (in reference to statement) but can't see it happening, they want people who can't stop gambling, why exclude them? And (P65) 'Nah, do pubs ban alcoholics? I mean unless they are violent...your keep serving them. Same here, they want us to keep punting'.

The statement 'Bookmakers should refuse bets from anybody that is clearly intoxicated' received a mixed response. Of the 72 customers 24 (33.3\%) strongly agreed, with 15 (20.8\%) agreeing, 14 (19.4\%) neither agreeing nor disagreeing, with 19 (26.3\%) disagreeing (intoxicated meant 'unable to make a rational decision'), with the customers justifying their views by claiming that (P6) 'it's impossible to tell with some people, and (P15) 'you gotta be careful, you can't start making judgement-calls on people, and (P37) 'alcohol affects us differently, and what are they gonna do at Christmas, ban most of us! The data further illustrated that there was an age difference with older customers emphasizing personal responsibility. Of the 19 (26.3\%) that disagreed with the statement 7 were from Category 5 (age range 51-60) and 12 from (Category 6, 61-70).

The statement 'Bookmakers should refuse bets if a person is gambling underage' secured condemnation with 65 (90.2\%) strongly agreeing and 7 agreeing (9.7\%). The following comments made it clear that this was considered clear exploitation. The reasoning behind this data was that underage gambling was taking advantage of immature, vulnerable 'young' people that had little or no money to lose, and might possibly contribute to criminal behaviour if addicted (Blaszczynski and McConaghy 1994; Meyer and Stadler 1999; Crofts 2003; Brooks and Blaszczynski, 2011). One customer made it clear when saying (P5) 'Knowingly taking money from a kid is unacceptable, it's the lowest of the low, I mean, adults, we're supposed to be responsible, but you can't exploit a kid'. This was repeatedly emphasized (P9) 'too young to know better...shouldn't be exposed to gambling so young...the worst thing that can happen is they win! A few of the customers further clarified their views and emphasized the irresponsible nature of letting underage people in bookmakers, (P24) 'Where do they get the money from? I mean most round here aren't working; is it from the dole (income support), or the family, that would be ridiculous! They could be committing crime for all we know'. 
The results from this research illustrate that those in category $5(n=23,31.9 \%)$ and in category 6 (61-70) $(n=21,29.1 \%)$ emphasized personal restraint and responsibility far more than other age ranges (See Table 1 below). It was noticeable that 8 out of the 11 customers that were unemployed played FOBTs, and those that frequented a bookmakers demanded 'a service' (placing bets near start of race(s), with infrequent customers seen as '(P14) 'In my way sometimes when I want to get a bet on! Due to the location of these bookmakers this research has a high percentage of people in the 51-70 age range, which is $61.1 \%$ of all customers, and many self-employed people $(n=23)$, which is $31.9 \%$ of all customers. These data, however, reflect the geographic and demographics of the location of the research. A similar study in a major city might produce different sets of data or confirm customers' views of what a duty of care should comprise and attitudes towards bookmakers.

Table 1: Key Findings

\begin{tabular}{|c|c|c|c|c|c|}
\hline $\begin{array}{l}\text { Age of } \\
\text { customers }\end{array}$ & $\begin{array}{l}\text { Employment/ } \\
\text { Status }\end{array}$ & Ethnicity/Gender & $\begin{array}{l}\text { Years } \\
\text { gambling }\end{array}$ & $\begin{array}{l}\text { Type of } \\
\text { gambling }\end{array}$ & $\begin{array}{l}\text { Frequency } \\
\text { of } \\
\text { gambling }\end{array}$ \\
\hline $\begin{array}{l}23 \text { customers } \\
(31.9 \%) \text { were } \\
\text { age } 51-60 \\
\text { and } 21 \\
(21.9 \%) \text { were } \\
61-70 . \text { A } \\
\text { combined } \\
\text { total of } 44 \\
\text { (61.1\%) of all } \\
\text { interviews. } \\
\text { came from } \\
\text { customers } \\
51-70 . \\
19 \text { (23.6\%) of } \\
\text { these two } \\
\text { groupings } \\
\text { emphasized } \\
\text { personal } \\
\text { responsibility } \\
\text { for gambling }\end{array}$ & $\begin{array}{l}23(31.9 \%) \\
\text { self-employed } \\
\text { and } 21 \\
(29.1 \%) \\
\text { retired. } \\
8 \text { out of } 11 \\
(72.7 \%) \\
\text { unemployed } \\
\text { played FOBTs } \\
\text { Category age } \\
\text { range } 51-70 \\
\text { highly critical } \\
\text { of FOBT in } \\
\text { bookmakers }\end{array}$ & $\begin{array}{l}\text { Of } 72 \\
\text { interviewed } \\
\text { none were } \\
\text { women. } \\
63 \text { customers } \\
\text { ( } 87.5 \%) \text { white } \\
\text { British reflecting } \\
\text { geographical } \\
\text { location of } \\
\text { research. } \\
11 \text { women } \\
\text { employed by } 7 \\
\text { bookmakers in } \\
\text { locations }\end{array}$ & $\begin{array}{l}\text { Of those } \\
\text { gambling } 20 \\
\text { years or more } \\
(n=41) 19 \\
(26.3 \%) \text { were } \\
\text { self- } \\
\text { employed, } 12 \\
(16.6 \%) \\
\text { employed, } 11 \\
(15.2 \%) \\
\text { retired. } \\
\text { Daily } \\
\text { gambling } \\
\text { ( } n=30) \\
\text { ( } 41.6 \%) \\
\text { explained as } \\
\text { form of } \\
\text { entertainment }\end{array}$ & $\begin{array}{l}61 \text { ( } 84.7 \%) \\
\text { customers } \\
\text { preferred } \\
\text { horseracing. } \\
\text { Bookmakers } \\
\text { referred to } \\
\text { as social } \\
\text { environment } \\
\text { to hold a } \\
\text { conversation } \\
\text { and seek } \\
\text { company } \\
\text { across all } \\
\text { age ranges }\end{array}$ & $\begin{array}{l}30 \\
\text { customers } \\
\text { (41.6\%) } \\
\text { gambling } \\
\text { daily of } \\
\text { which } 14 \\
\text { (46.6\%) } \\
\text { were self- } \\
\text { employed } \\
\text { No } \\
\text { customers } \\
\text { referred to } \\
\text { themselves } \\
\text { or others } \\
\text { as } \\
\text { gambling } \\
\text { addicts in } \\
\text { research } \\
\text { even } \\
\text { though } \\
\text { frequency } \\
\text { of } \\
\text { gambling } \\
\text { indicated } \\
\text { this as } \\
\text { potential } \\
\text { problem }\end{array}$ \\
\hline
\end{tabular}


Regardless of the location of this research, however, the implications for practice regarding customers' knowledge and expectations of what a duty of care should comprise and what is currently offered is substantially different. Many customers were unaware of what a duty of care meant, its process, the expectations on the bookmakers and how to apply for self-exclusion. Most responses (see earlier) had some vague reference to (P3) 'a system to protect me from myself' but no notion of what that system might offer in practice. Since customers are needed for bookmakers to secure a profit and the Gambling Commission requires such businesses to offer 'socially responsible gambling', we suggest that a high profile advertising campaign promoting what a duty of care is, what it should include, and how self-exclusion is accessed is a requirement of all gambling establishments, which the Gambling Commission could demand beyond current levels of promoting duty of care information.

\section{Conclusion}

This paper illustrates that customers' views coalesce around key themes but are not necessarily uniformed in nature regarding a duty of care. A range of customers' views were sought because a duty of care reaches beyond selfexclusion. This issue has been well documented but little research has been conducted on customers' views and awareness of what a duty of care is or should contain. This is, we argue needed, as current customers, and those yet to start gambling, are those with a potential gambling problem in the future. Research indicates that location, opportunity and placement of gambling establishments (Blaszczynski 2005; Fernandez-Alba and Labrador 2005) contribute to the potential for problem gambling and the spatial location (density and distribution) of gambling venues and interplay of environment, opportunity and individual predisposition (Welte et al. 2007) all affect the propensity to engage in gambling, and subsequently negative consequences of excessive gambling.

However, courts of law adopt a different perspective where the individual is the primary focus of attention and consequently responsible for his or her past, present and future actions. Whilst the majority of customers in this research are aware of this, and some emphasized individual responsibility to proximal and environmental factors, the customers interviewed were critical of bookmakers but still continued to engage in gambling. Aware that the chances of winning were minimal many referred to gambling as entertainment, as a justification for 'purchasing' a service that often failed to deliver. Many, however, were gambling on a daily basis ( $n=30,41.6 \%)$ and whilst none (that we were aware of) had requested self-exclusion, this level of gambling indicates a future potential health issue. 


\section{References}

Bauer, J. (2006). Self-Exclusion and The Problem Gambler: The House shouldn't Always Win. Northern Illinois University Law Review, 27, 63-93.

Bulmer, M. (2003). Sociological Research Methods: An Introduction. New Jersey: Transactions Press.

Belaisha, B., B. and Brooks, G. (2014). Money Laundering in Dubai: Strategies and Future Directions. Journal of Money Laundering Control, 17 (3), 343-354.

Bernardi, S. and Pallanti, S. (2009). Internet addiction: a descriptive clinical study focusing on comorbidities and dissociative symptoms. Comprehensive Psychiatry, 50 (6), 510-516

Blaszczynski, A. (2005). To formulate gambling policies on the premise that problem gambling is an addiction may be premature. Addiction, 100, 1230-1231.

Blaszczynski, A. and McConaghy, N. (1994). Criminal offences in Gamblers Anonymous and hospital treated pathological gamblers. Journal of Gambling Studies, 10(2), 99-127.

Brooks, G. (2012). 'Online gambling and money laundering: 'views from the inside'. Journal of Money Laundering Control, 15 (3), 304-315.

Brooks, G., and Blaszczynski, A. (2011). Judicial decisions on cases involving problem gambling and crime in England and Wales'. International Gambling Studies, 11 (1), 81-93

Calvert v William Hill Credit Ltd [2008] EWHC, Chapter 454.

Cameron, J. (2007). Problem gamblers and the Duty of Care: A Response to Sasso and Kalajdzic'. Gaming Law Review, 11 (5), 554-571.

Collins, P. and Kelly, J. (2002). Problem Gambling and Self- Exclusion: A Report to the South African Responsible Gambling Trust. Gaming Law Review 6 (6), 517531.

Corney, R., and Davis, J. (2010). The attractions and risks of Internet gambling for women: A qualitative study. Journal of Gambling Issues: Issue 24, pp. 121-139.

Crofts, P. (2003). Problem gambling and property offences: An analysis of court files. International Gambling Studies, 3(2), 183-197.

Crowne, E. (2008). The Problem with Problem Gaming: A Response to Sasso and Kalajdzic, in Defense of the Gaming Industry. Gaming Law Review and Economics, 12 (4), 340-343. 
Faregh, N., and Leth-Steensen, C. (2009). Reflection on the Voluntary Self Exclusion of Gamblers and the Law Suits against Ontario Lottery and Gaming Corporation. Journal of Gambling Studies, 25 (2), 131-138.

Farooq, K., and Brooks, G. (2013). Arab fraud and corruption professionals' views in the Arabian Gulf. Journal of Financial Crime, 20 (3), 338-347.

Fernandez-Alba, A., and Labrador, F. (2005). Socio-demographic, psychopathological and clinical characteristics of pathological slot-machine gamblers in treatment: A descriptive study of Spanish male gamblers. International Gambling Studies, 5(1), 113-122.

Gainsbury, S., M (2014). Review of Self exclusion from Gambling Venues as an Intervention for Problem Gambling. Journal of Gambling Studies, 30 (2), 229251.

Gambling Commission (2012). Survey data on gambling participation. Gambling Commission: Birmingham, United Kingdom

Gambling Commission (2014). Gambling Codes of Practice: Consolidated for all Forms of Gambling. Gambling Commission: Birmingham, United Kingdom.

Hayer, T. and Meyer, G. (2011). Self-Exclusion as a Harm Minimisation Strategy: Evidence for the Casino sector from Selected European Countries. Journal of Gambling Studies, 27 (4), 685-700.

Kalajdzic, J. (2008). Cameron's Rejection of a Duty of Care to Problem Gamblers: A problematic Defense of Ontario's Gaming Industry'. Gaming Law Review, 12 (1), 55-59.

Ladouceur, R., Jacques, C., Giroux, I., Ferland, F., and LeBlond, J (2000). Brief Communications Analysis of a Casino's Self-Exclusion Program. Journal of Gambling Studies, 16 (4) 453-460.

Ladouceur, R., Sylvain, C., and Gosselin, P. (2007). Self-Exclusion Program: A Longitudinal Evaluation Study. Journal of Gambling Studies, 23 (1), 85-94.

McNeilly, D. P. and Burke, W., J (2000). Late Life Gambling: The Attitudes and Behaviours of Older Adults. Journal of Gambling Studies, 16 (4), 393-415

Meyer, G., and Stadler, M. (1999). Criminal behaviour associated with pathological gambling. Journal of Gambling Studies, 15(1), 29-43.

Mohammed, E. (2008). The problem with Problem Gaming: A response to Sasso and Kalajdzic, in Defense of the Gaming Industry'. Gaming Law Review and Economics, 12 (4), 340-343. 
Napolitano, F. (2003) The Self Exclusion Program: Legal and Clinical Consideration. Journal of Gambling Studies 19 (3), 303-315.

Nelson, R. (2003). Gambling and the Law - Compulsive Gamblers Lose Again, in Court'. Gaming Law Review, 7 (6).

Nelson, S, E., Debi, A. La Plante, Allyson, A, J., Schumann, A., LaBrie, R., and Shaffer, H., J. (2008). Real Limits in the Virtual World: Self Limiting Behaviour of Internet Gamblers. Journal of Gambling Studies, 24 (4), 463-477.

Nelson, S, E., Kleschinsky, J., H, LaBrie, R., Kaplan, S, and Shaffer, H., J. (2010). One Decade of Self Exclusion: Missouri Casino Self Excluders Four to ten Years After Enrolment. Journal of Gambling Studies, 26 (1), 129-144.

Orford, J. (2001). Excessive Appetites: A Psychological View of Addictions. Chichester: Wiley.

Osanic, P. (2002). An examination of the potential for finding government liability in the context of compulsive gambling'. Gaming Law Review, 6 (3), 229242.

Rhea, A. (2005). Voluntary Self-Exclusion Lists: How They Work and Potential Problems'. Gaming Law Review 9 (5), 462-469.

Sasso, W. and KalaJdzic, J. (2008). Do Ontario and its Gaming Venues Owe a Duty of Care to Problem Gamblers?' Gaming Law Review, 10 (6).

Wardle, H., Moody, A., Spence, S., Orford, J., Volberg, R., Jotangia, D., Griffiths, M., Hussey, D., and Dobbie, F. (2011). Gambling Prevalence Survey. London: NatCen.

Welte, J.W., Barnes, G.M., Wieczorek, W., Tidwell, Marie-Cecile O., \& Hoffman, J.H. (2007). Type of gambling and availability as risk factors for problem gambling: A Tobit regression analysis by age and gender. International Gambling Studies, 7(2), 183-198.

Widyanto, L and Griffiths, M (2006). 'Internet Addiction': A Critical Review. International Journal of Mental health and Addiction, 4 (1), 31-51. 